\title{
RADIOCARBON DATES AND ARCHAEOLOGY OF THE LATE PLEISTOCENE IN THE JAPANESE ISLANDS
}

\author{
Akira Ono ${ }^{1,2} \bullet$ Hiroyuki Sato ${ }^{3}$ Takashi Tsutsumi ${ }^{4} \bullet$ Yuichiro Kudo $^{1}$ \\ ABSTRACT. We discuss the radiocarbon chronology of Late Pleistocene archaeology in the Japanese islands. In sum, 429 \\ samples from more than 100 archaeological sites were compiled and then divided into three periods and four stages. The Early \\ Upper Paleolithic, characterized by Trapezoid industries, lasted during approximately 34-26 ka. The Late Upper Paleolithic \\ period includes both the backed-blade stage and point-tool stage, the latter appearing chronologically later than the former. \\ This stage covers $\sim 25-15 \mathrm{ka}$. The Final Upper Paleolithic and Incipient Jomon are distinguished by the appearance of micro- \\ blade industries and the emergence of pottery at the end of this period. This period covers approximately 14-12 ka. The \\ microblade tradition, in the broadest sense, is strongly connected to the background of peopling of the New World. New data \\ on the transitional stage from the Middle to the Upper Paleolithic are also discussed in regards to three archaeological sites. \\ Issues on the application of the ${ }^{14} \mathrm{C}$ calibration to the whole Japanese Upper Paleolithic are critically evaluated.
}

\section{INTRODUCTION}

The intent of this paper is to clarify the background of the peopling of the New World in relation to the archaeological records, with particular emphasis on radiocarbon dates from the Japanese islands. Chronometric foundations of the Japanese Upper Paleolithic have been developed during the last three decades. Compilation of ${ }^{14} \mathrm{C}$ dates, together with the stratigraphic sequence of lithic industries, illustrates the board-spectrum of the background of the topic (Kuzmin et al. 1998).

Some framework should be noted. First, we discuss the Japanese Upper Paleolithic in as simplified a way as possible in an attempt to summarize and focus on the relevant subjects. Second, we limit the geographical area within the Japanese islands. Although this area reflects only the boundaries of the present nation state, we have kept this framework because most of the Japanese Paleolithic research has been carried out in this field since 1949. Third, the time range of this paper covers the final phase of the Middle Paleolithic to the entire Upper Paleolithic and Incipient Jomon, i.e., the latter half of OIS3 to the end of OIS2. The criterion for the subdivision of the Japanese Paleolithic are controversial in regards to whether they should be divided into three or two periods (Sato 2001). The term used here, "final phase of the Middle Paleolithic" indicates in any case a phase before the emergence of the blade technique. Fourth, the ${ }^{14} \mathrm{C}$ results cited in this paper are uncalibrated dates despite the conventional or accelerator mass spectrometry (AMS) determinations. Prior to the advent of AMS, conventional ${ }^{14} \mathrm{C}$ dates for the Upper Paleolithic in Japanese islands were of variable quality.

\section{THE PRESENT STATE OF RADIOCARBON DATING}

The number of Pleistocene sites in the Japanese islands has been estimated at 4500. Each year, more than 100 additional sites are excavated. However, not many of these sites have been dated by the ${ }^{14} \mathrm{C}$ method (see Table 1 in Appendix).

Almost all Japanese Late-Pleistocene archaeological sites belong to the Upper Paleolithic with the exception of some Middle Paleolithic sites (Ono et al. 1992; Japan Association for Quaternary Research 1987). The reasons why there are few examples of ${ }^{14} \mathrm{C}$ dating in the Late Pleistocene of the Japanese islands are as follows.

\footnotetext{
${ }^{1}$ Archaeology Laboratory, Tokyo Metropolitan University, Minami-Osawa 1-1, Hachioji, Tokyo, Japan

${ }^{2}$ Corresponding author. Email: ono@bcomp.metro-u.ac.jp.

${ }^{3}$ Department of Archaeology, University of Tokyo, Hongo 7-3-1, Bunkyo-ku, Tokyo, Japan

${ }^{4}$ Archaeological Heritage Section, Miyota Board of Education, Miyota-machi 2663-2, Kitasaku, Nagano Prefecture, Japan
} 
First, the establishment of the local chronology within the Japanese islands has to be mentioned. Many Upper Paleolithic sites have been excavated since the first Paleolithic excavation was carried out at the Iwajuku site in Gunma Prefecture in 1949. The massive volcanic eruptions in the Pleistocene are traceable in many archaeological layers. Extensive studies of the tephrochronology have clarified the distinctive cultural layers in thick loam with many marker-tephra (Machida and Arai 1992). Widely distributed key tephra covered almost all the Japanese islands and they functioned as the time-marker. Archaeological artifacts from different areas have been combined and given exact chronological positions (Machida et al. 2000). At the same time, the archaeological chronology of each area has been completed by the progression of techno-typological studies of lithic artifacts.

Second, the persistent condition of carbonized materials for ${ }^{14} \mathrm{C}$ dating in the Japanese Late Pleistocene under the periglacial environment provides fewer advantages for preservation. Cultural layers consist of acid soils that originated from volcanic ash, and no organic materials such as wood or bone are preserved at all. In the early period of ${ }^{14} \mathrm{C}$ dating, results often conflicted with the archaeological chronology. At that time, the effectiveness of ${ }^{14} \mathrm{C}$ dating was questioned by many archaeologists because of the inconsistency of sampling bias and preservation issues before the 1970s.

Third, Japanese Paleolithic research began in pursuit of the regional chronology, and comparative studies between neighboring Asian countries were not active before the 1980s. Over the past two decades, research developments in China, Korea, and the Russian Far East have forwarded the development of intercontinental chronological comparison both by morpho-typological and ${ }^{14} \mathrm{C}$ dating.

\section{KEY RADIOCARBON DATES OF THE UPPER PALAEOLITHIC}

\section{Chronology of the Upper Paleolithic in the Japanese Islands}

Upper Paleolithic chronological studies have been advanced in most areas that have well-stratified thick loam layers made up of volcanic ash, aeolian dust/or loess from China, and fine sand blown in from river terraces near the studied area. In the central part of the Japanese islands, and in the Tokyo area in particular, detailed chronologies have been established both on a stratigraphic and a morphotypological basis. The widely distributed key marker tephra provides excellent chronological synchronicity among separated areas. The basic chronological sequence of the Upper Paleolithic follows four stages: 1) in the early phase, trapezoid industries covered whole Japanese islands; 2) backed-blade industries became common and stable during the early-to-later phase of the Upper Paleolithic; 3) point-tool industries have developed particularly in Central Japan; and 4) microblade industries have successfully spread over the Japanese islands until the emergence of incipient Jomon cultural elements.

The distinction between the Early and Late Upper Paleolithic is characterized as the formation of local varieties of lithic assemblage and social change, reflecting settlement patterns, and this occurred in the middle phase of the backed-blade sequence.

The huge volcanic eruption occurred from the Aira caldera, south Kyushu, in the following sequence. The eruption spread volcanic ash over most of the Japanese islands as well as the Korean peninsula, a part of east China, and southern Primorye in the Russian Far East. This key tephra is called Aira-Tn tephra (AT), which is critically important for the Upper Palelithic chronology. Recent AMS determination of the AT-tephra was found to be 25-24 ka (Japan Association for Quaternary Research 2000). This time range coincides well with the transition from OIS3 to OIS2, which includes LGM period. Key ${ }^{14} \mathrm{C}$ dates are compiled in Table 1 . The table lists 429 samples from more than 100 archaeological sites. Figure 1 shows the chronology of Upper Paleolithic development of lithic assemblage. 


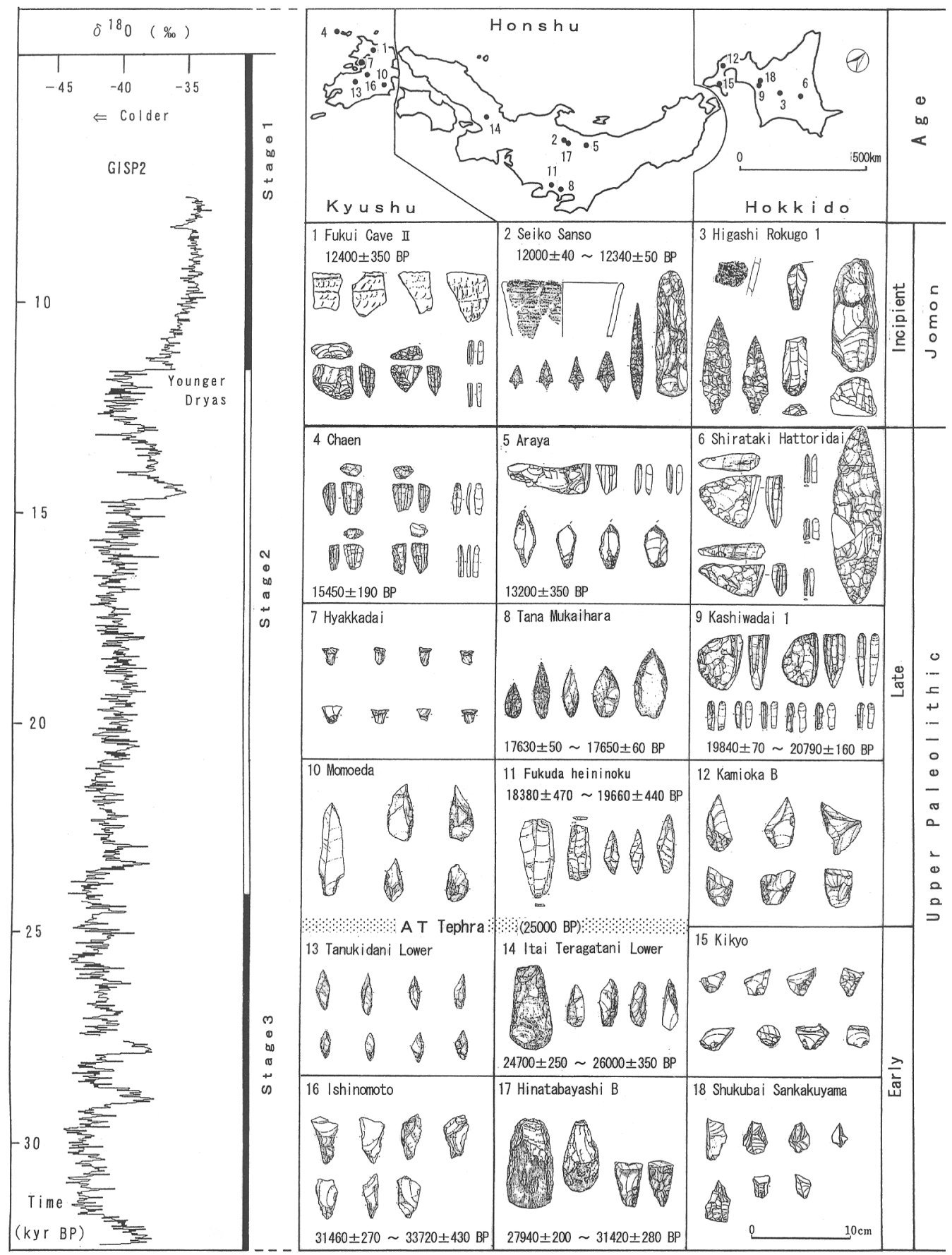

Figure 1 Chronology and ${ }^{14} \mathrm{C}$ dates of the Upper Paleolithic and Incipient Jomon in the Japanese islands. Left: climatic change shown by the $\delta^{18} \mathrm{O}$ record of the GISP2 ice core (after Stuiver and Grootes 2000). Note that the ${ }^{14} \mathrm{C}$ dates of archaeological sites are uncalibrated AMS measurements. 


\section{Early Upper Paleolithic: 34-26 ka}

The earliest period of the Upper Paleolithic is distinguished by trapezoidian lithic industries of in which trapezoids and edge-round stone tools were used (Sato 1992). One of the representative sites from the Kyushu, the Ishinomoto site (Figure 1:16), is AMS dated to 31,460 $\pm 270 \sim 33,720 \pm 430 \mathrm{BP}$ (Ikeda 1999). Sixty edge-ground stone tools (axes) and many trapezoids have also been excavated from the early Upper Paleolithic site Hinatabayashi B (Figure 1:17) in north-central Japan. Its AMS determination was 27,940 $\pm 200 \sim 31,420 \pm 280 \mathrm{BP}$ (Tsuchiya and Tani 2000). These ${ }^{14} \mathrm{C}$ dates suggest that the beginning of the Japanese Upper Paleolithic is older than $30 \mathrm{ka}$.

In the later phase of the early period of the Upper Paleolithic, Hatsunegahara, a unique open-air site, explicitly showed that 56 trap-pits with almost $1.5-\mathrm{m}$ depths have been unearthed beneath the AT tephra horizon. These provide key evidence for re-evaluating the site function as well as the hunting system in the Upper Paleolithic. ${ }^{14} \mathrm{C}$ dates detected from the bottom of one of these pits show 27,200 BP and 29,750 $\pm 210 \mathrm{BP}$ (Suzuki and Maejima 1999). The foundation of these trap-pits can therefore be suggested between $27 \mathrm{ka}$ and $25 \mathrm{ka}$.

In the western part of the Japanese islands, an industry from the lower cultural horizon of the ItaiTeragatani site is a representative one that belongs to the later phase of early Upper Paleolithic. ${ }^{14} \mathrm{C}$ dates from this site were 24,700 $\pm 250 \mathrm{BP}$ and 26,000 $\pm 350 \mathrm{BP}$ (Yamaguchi and Kishimoto 1991). Though the edge-ground stone tools (axes) and backed-blades have been excavated from this site, a specific "Setouchi technique," characterized by an oblong blade-detaching or a side-blow flaking technique, in western Japan in particular, had already emerged in its germinal stage.

The foundation of the "Setouchi technique" could threfore suggest that it can be set back to 26$25 \mathrm{ka}$. Contrary to the "Setouchi side-blow technique", the blade technique was developed in the latter half of the early Upper Paleolithic in eastern Japan.

\section{Late Upper Paleolithic: 25-15 ka}

After the huge AT ash fall, i.e., in the latter half of the Upper Paleolithic, the upper cultural layer of the Itai-Teragatani site contains backed blades and many denticulated points (Kakusuijo-sekki). ${ }^{14} \mathrm{C}$ measurement of the peat layer, which is included these lithic industries, indicates $22,700 \pm 330 \mathrm{BP}$ and 20,400 $\pm 260 \mathrm{BP}$. The Tomizawa site in northern Japan also belongs to the latter Upper Paleolithic. A buried forest was discovered at this site with backed-blades and a fireplace. This is a unique hunting site that has great potential for reconstructing the paleoenvironment and human activities in the Upper Paleolithic (Ota 1992). ${ }^{14} \mathrm{C}$ dates from the site are 23,870 $\pm 860 \mathrm{BP}$ and $19,430 \pm 400 \mathrm{BP}$, and these fall in the LGM period. In the same horizon around Tomizawa, the subarctic coniferous buried forest of Picea has been excavated. There, droppings of Shika deer (Cervus nippon) and the fossils of insects that lived in the aquatic environment have been found.

After backed-blades diminished in the later Upper Paleolithic, point-tool industries came about mainly in central Japan. These bifacially retouched leaf shape points are usually about $10 \mathrm{~cm}$ long. Two dwelling structures were recently excavated at the Kogure-Higashi-Arayama site in Gunma Prefecture and at the Tana-Mukaihara site in Kanagawa Prefecture. The two dwelling sites belong to the point-tool industry and AMS determination indicates that the former is 17,950 $\pm 60 \mathrm{BP}$ (Hosono 1999), and the latter are 17,650 \pm 60 and 17,630 $\pm 50 \mathrm{BP}$ (Tsuji 2000). As a result of these measurements, point-tool industries can be dated back to about 18-17 ka. 


\section{Final Upper Paleolithic and the Incipient Jomon: 14-12 ka}

The microblade industry represents the final period of the Upper Paleolithic in the Japanese islands. The sites of Yasumiba 14,300 \pm 700 BP (Sugihara and Ono 1965), Araya (Figure 1:5) 13,200 \pm 350 BP (Serizawa 1959), and Tsukimino-Kamino 13,570 $\pm 410 \mathrm{BP}$ (Aida 1986) offer key ${ }^{14} \mathrm{C}$ dates for this period. Contrary to these dates, recent AMS determination at the Kashiwadai site (Figure 1:9) in Hokkaido reveals 20,790 $\pm 160 \sim 19,840 \mathrm{BP}$. These results imply that the microblade industry in Hokkaido, at the northern extreme of the Japanese islands, begins with about 21-20 ka, and this means a few thousand years earlier than Honshu area (Fukui and Koshida 1999). In Chaen at the extreme southern tip of the Kyushu (Figure 1:4), an early microblade industry dated to 15,450 \pm 190 BP (Kawamichi and Araki 1998).

The duration of microblade industries in Kyushu covers approximately 15-12 ka, and in the latter phase of this period nail-patterned incipient Jomon pottery had already been associated with the microblade technique at the Fukui cave site Layer II (Figure 1:1). A ${ }^{14} \mathrm{C}$ date at Fukui cave is 12,400 \pm 350 BP (Kamaki and Serizawa 1965).

New AMS dates have recently become available for the terminal Upper Paleolithic and/or the incipient phase of Jomon. The earliest undecorated pottery and the Mikoshiba-type axe, with its humped cross-section and points, have been excavated at the Odai-Yamamoto site in the northern extreme of the Japanese main island Honshu. Carbon adhesions on pottery fragments were dated by AMS and the results are shown as 13,780 $\pm 170 \sim 12,680 \pm 140$ BP (Taniguchi 1999). Furthermore, carbon adhesions on linear-relief pottery from the Seiko-Sanso site in central-northern Japan have also been tested by AMS, and the results are 12,340 $\pm 50 \sim 12,000 \pm 40$ (Tsuchiya and Nakajima 2000). Direct AMS dating of carbon adhesions on the earliest potsherds shows that the emergence of pottery in the Japanese islands dates from $\sim 13,000 \mathrm{BP}$

It should be emphasized that the Upper Paleolithic of the Japanese islands began before $\sim 30 \mathrm{ka}$ and developed for over 20,000 years before diminishing in the transition to the Jomon age at about $13 \mathrm{ka}$.

\section{DISCUSSION}

\section{The Origin of Blade and Microblade Technology in Hokkaido: Kashiwadai 1 Site}

Hokkaido is located at the northern tip of the Japanese islands. The soil formation there was not well developed in the later Pleistocene. Lithic artifacts from different periods, therefore, were sometimes unearthed from the same layer. Recently, however, the result of good carbonized materials of AMS determination from fireplaces allows one to re-examine the chronology of the microblade industry that had been established mostly by typological classification of cores and reduction technology.

In the case of the Kashiwadai 1 site, Chitose City in Hokkaido, the carbonized materials of 13 samples were found in fireplaces associated with lithic concentrations and Rankoshi-type microblade cores. AMS results are 20,790 \pm 160 to 19,840 $\pm 70 \mathrm{BP}$. The mean value is $\sim 20,500 \mathrm{BP}$ (Hokkaido Center for Archaeological Operations 1999). This indicates the Rankoshi-type microblade core is older than the Shirataki type.

The detaching face of the Rankoshi type is set on the long axis, but the Shirataki type is set on the minor axis. This change so far seemed to be caused by gradual evolution of the effective utilization of raw materials. Furthermore, the blade technique is evident in the initial flaking stage of the Rankoshi micro core production in Kashiwadai 1 Site. Therefore, the emergence of the blade technique in Hokkaido suggested that it was older than $20 \mathrm{ka}$. The first appearance of microblade industry in 
Hokkaido, in this context, seems to show no large time discrepancy compared to East Siberia, and inflow of microblade industries to Hokkaido was comparatively earlier than in other parts of the Japanese islands. Hokkaido microblade industries might have shared the same cultural traditions of East Siberia. These cultural traditions, in the broadest sense, are strongly connected to the theme of peopling the New World crossover to the Beringia.

\section{New Data on the Transitional Stage from Middle to Upper Paleolithic}

\section{The Lake Nojiri Site Group}

Lake Nojiri in central north Japan lies in the flat highland of the northern Fossa Magna at $654 \mathrm{~m}$ above sea level. The Nojiriko Formation is divided into three members: the Lower, Middle, and Upper, with marked inconformities. Furthermore, each member is subdivided into three or four parts. The chronometric framework of the Nojiri-ko Formation can be attributed as follows by AMS determination: the Lower Member covers 50,000-42,000 BP, the Middle Member covers 42,00035,000 BP, and the Upper Member covers 35,000-12,000 BP (Sawada et al. 1992). The Tategahana site on the shore of Lake Nojiri is, in particular, is unique with well-preserved organic materials.

Most of the mammal fossils are made up of two species. Bones of Naumann's elephant (Palaeoloxodon naumanni) represent 91.9\%, and Yabe's giant deer (Sinomegaceros yabei) form 7.9\% of the total mammal fossils. This faunal assemblage suggests that the selective big game hunting by Paleolithic hunters reflected the composition of the faunal remains. Lithic tools and flakes such as scrapers and drills have been excavated with bone materials in the same layer. In the Middle Nojiri-ko, Member I in particular, a bone cleaver and refitted bone flake with retouched base, and refitted bone chips were also found at same concentration. All bone tools were made by direct flaking, but the socalled "groove and splinter technique" had not yet appeared (Ono 2001). These pieces of evidence suggest that the site functioned as a killing and butchering place on a lake shore in the final stage of Middle Paleolithic (Nojiri-ko Excavation Research Group 1984, 1994; Ono and the Nojiri-ko Excavation Research Group 1991).

\section{Ishinomoto Site}

A recent investigation of South Kyushu reveals new aspects of the early Upper Paleolithic. More than 3000 lithic artifacts have been unearthed at the Ishinomoto site in Kumamoto Prefecture. This industry includes many trapezoids that have distinguishing features of the early Upper Paleolithic viewed from the techno-typology (Sato 1992). AMS dates (33,720 \pm 430 and 31,460 $\pm 270 \mathrm{BP}$ ) are reported (Ikeda 1999), and these are good examples of the beginning of the Upper Paleolithic.

Trapezoid industries are possible to evaluate as an index of the early Upper Paleolithic from Kyushu to Hokkaido. At the same time, some characteristic industries were discovered from Kyushu as shown below.

\section{Yokomine C, Tachikiri, and Ushiromuta Sites}

At Tanegashima island, in the ocean to the south of Kyushu, three pebble clusters, some pounding stones, and pebble tools were excavated from the early Upper Paleolithic cultural layer I (Dogome 1998). AMS dates for carbonized materials from the pebble clusters are 31,280 \pm 690 and 29,670 \pm 540 BP. Another AMS determination from cultural layer II is 30,490 \pm 590 . The stratigraphic level of this horizon is just above the Tane IV volcanic ash, and found three pebble clusters and anvil stones, pounding stones, grinding stones, and flakes (Sakaguchi and Dogome 2000). 
The same chronological layer to the culture layer I of Yokomine C site, a pebble cluster, two pits, 14 fire places, and about 50 stone tools were excavated from Tachikiri site. An AMS date for this site is $30,480 \pm 210 \mathrm{BP}$.

The Ushiromuta site also has many grinding and pounding stones from culture layer III, and four AMS dates are available from 30,290 \pm 200 to $28,900 \pm 150$ BP (Sato 1999). These industries are very different from other parts of Japan (Tachibana 1999) and they suggest that the early Upper Paleolithic people had adapted to the plant resource acquisition strategy. This should be a key to discuss the possibilities of a southern route of peopling modern humans to the Japanese islands.

\section{CONCLUSION}

We discussed mainly the determination of the chrono-stratigraphic sequence of the Upper Paleolithic of the Japanese islands by ${ }^{14} \mathrm{C}$ dating. Recent progress and the increasing number of AMS dates bring about a new horizon in ${ }^{14} \mathrm{C}$ dating for a whole range of the Upper Paleolithic. High-precision ${ }^{14} \mathrm{C}$ dates and their calibration lead us to new critical issues with particular reference not only to the framework of the Pleistocene/Holocene transition, but the Paleolithic/Jomon transition. In this paper, ${ }^{14} \mathrm{C}$ dates have been discussed with uncalibrated ones. When the calibration applied to the earliest pottery such as the Odai-Yamamoto I site, the dates calculate between 16,500 and 16,000 cal BP. This suggests that the earliest potteries in East Asia are preceded by the Oldest Dryas period in terms of northwest Europe. ${ }^{14} \mathrm{C}$ dating is widely applicable among different disciplines. Correlations between high-precision dating, calibration, exact sampling from the sound archaeological context and their interpretations are, therefore, more critically evaluated.

\section{ACKNOWLEDGMENTS}

We are greatful to Dr T Soda of the Palaeoenvironment Research Laboratory, Maebashi, Japan, for constructive comments on the marker-tephra.

\section{RERERENCES}

Aida K, editor. 1986. Kamino site Location 1 in the Tukimino site group. Archaeological Research Reports of Yamato City, No. 21. Yamato City Board of Education. In Japanese.

Dogome H. 1998. Paleolithic culture in Tanegashima Island. In: Proceedings of the annual meeting of the Japanese Archaeological Association. p 17-26. In Japanese.

Fukui J, Koshida K, editors. 1999. Kashiwadai 1 Site: Hokkaido. Hokkaido Archaeological Research Center. Research Reports, No. 138. Hokkaido Archaeological Research Center. In Japanese.

Hokkaido Center for Archaeological Operations. 1999. Kashiwadai 1 Site. In Japanese.

Hosono T. 1999. Excavations at Kogure-HigashiArayama site. In: The 11th Meeting for Paleolithic Culture Research in Nagano Prefecture. Abstracts. In Japanese.

Ikeda T, editor. 1999. Ishinomoto site group (II). Kumamoto. Archaeological Research Rreports of Kumamoto Prefecture, No. 178. Kumamoto Prefectural Board of Education. In Japanese.

Japan Association for Quaternary Research, editors.
1987 Quaternary Maps of Japan. University of Tokyo Press: Tokyo. In Japanese.

Japan Association for Quaternary Research, editors. 2000. ${ }^{14} \mathrm{C}$ ages of the Japanese Prehistory.

Kamaki Y, Serizawa C. 1965. The rock-shelter of Fukui, Nagasaki prefecture. Kokogaku Syukan 3(1):1-14. In Japanese.

Kawamichi H, Araki N, editors. 1998. Chaen site. Kishiku town board of education archaeological research reports, No. 3. Nagasaki. Kishiku town Board of Education. In Japanese.

Kuzmin YV, Ono A, Sato H, et al. 1998. Radiocarbon chronology of the stone age of northeast Asia. Vladivostok.

Machida H, Arai F. 1992. Atlas of Tephra in and around Japan. Tokyo: University of Tokyo Press. In Japanese.

Machida H, Arai F, Moriwaki H. 2000. Basics of stratigraphy. Tokyo: Tokyo-Bijutsu. In Japanese.

Nojiri-ko Excavation Research Group. 1984. The Lake Nojiri Excavation 3. The Association for the Geological Collaboration in Japan, Monograph 27: 267. In Japanese with English abstract.

Nojiri-ko Excavation Research Group. 1994. The Late 
Quaternary environment around Lake Nojiri in central Japan. Proceedings of the 29th International Geological Congress, Part B:269-77.

Ono A, Harunari H, Oda S, editors. 1992. Atlas of Japanese archaeology. Tokyo: University of Tokyo Press. In Japanese.

Ono A. 2001. Flaked bone tools: an alternative perspective on the Palaeolithic. Tokyo: Tokyo University Press. 290 p. In Japanese with English abstract.

Ono A, the Nojiri-ko Excavation Research Group. 1991. Archaeology of Lake Nojiri: a kill-butchering site of central north Japan in Later Pleistocene. In: Harding $\mathrm{JL}$, editor. The INQUA International Symposium on Stratigraphy and Correlation of Quaternary Deposits of the Asian and Pacific Regions. CCOP/TP 22:15966.

Ota A, editor. 1992. Tomizawa site. Sendai city board of education research reports, No. 160. Miyagi : Sendai city Board of Education. In Japanese with English abstract.

Sakaguchi K, Dogome H, editors. 2000. Yokomine C site. Kagoshima: Minamitane-cho Board of Education. In Japanese.

Sato H. 1992. Structure and evolution of Japanese Paleolithic culture. Tokyo: Kashiwa-Shobo. In Japanese.

Sato H. 1999. The transition from Middle to Late Paleolithic in southwestern Japan. In: From Souzudai to Kamitakamori: world Views on the Early and Middle Palaeolithic in Japan. Sendai: Tohoku Fukushi University. p 73-8. In Japanese.

Sato H. 2001. Do the Lower and Middle Paleolithic present in Japan after the Fujimura's scandal? Kagaku 71(4):5. In Japanese.

Sawada K, Arita Y, Nakamura T, Akiyama M, Kamei T, Nakai N. 1992. ${ }^{14} \mathrm{C}$ dating of the Nojiri-ko Formation using accelerator mass spectrometry. Earth Science 46(2):133-42. In Japanese with English abstract.

Serizawa C. 1959. A new Microblade industry discovered at the Araya site and the Araya-type Graver. The
Quaternary Research 1(5): 174-81. In Japanese.

Stuiver M, Grootes PM. 2000. GISP2 oxygen isotope ratios. Quaterrnary Research 53:277-84.

Sugihara S, Ono S. 1965. Microblade culture from the Yasumiba site in Shizuoka Prefecture. Kokogaku Shukan 3(2):1-33.

Suzuki T, Ito T, Maejima H, editors. 1999. Hatunegahara site. Shizuoka: Mishima City Board of Education. In Japanese.

Tachibana M. 1999. The Paleolithic culture in southern Kyushu: recent researche on the early upper Paleolithic in Kagoshima prefecture. Kagoshima-Kouko 33:59-73. In Japanese.

Taniguchi Y, editor. 1999. Archaeological research at the Odai Yamamoto I site: inquiry into the question of the end of the Palaeolithic culture and the beginning of the Jomon culture. Aomori: Odai Yamamoto I Site Excavation Team. In Japanese with English abstract.

Tsuchiya T, Nakajima E, editors. 2000. Seiko Sanso A, Seiko Ssansou B, Nishioka A, Kanoki, Uenohara, Okubo-minami, Higashiura, Uranoyama, Harinoki, Odaira B, Hinatabayasi A, Hinatabayasi B, Nanatsuguri and Fukoda sites. Nagano archaeological research center research reports, No. 49. Nagano: Nagano Prefectural Archaeological Research Center. In Japanese.

Tsuchiya T, Tani K, editors. 2000. Hinatabayashi B, Hinatabayashi A, Nanatsuguri, and Ohira B sites. $\mathrm{Na}$ gano archaeological research center research reports, No. 15. Nagano: Nagano Archaeological Research Center. In Japanese.

Tsuji S. 2000. From radiocarbon dates to calender years: for the estabilishment of chronologies in 21st century. In: Kawai N, editor. A chronicle of archaeology 2000. Asahi Shinbun.

Yamaguchi T, Kishimoto K. 1991. Itai-Teragatani site. Archaeological reports of Hyogo prefecture, No. 96. Hyogo: Hyogo Prefectural Board of Education. In Japanese. 


\section{APPENDIX}

\section{REFERENCES FOR TABLE 1}

$(\mathrm{J})=$ in Japanese. $(\mathrm{J} / \mathrm{E})=$ in Japanese with English abstract.

[1] Akashi H, Goto Y, editors. 1978. Kamiitaira site. Obihiro city Board of Education. (J)

[2] Oba T, Matsushita W. 1965. Preceramic age of Hokkaido. The Archaeology of Japan. Vol.1. Kawade-shobo. (J)

[3] Ueno S, Miyatsuka Y. 1981. Mosanru site. Shimokawa-cho Board of Education. (J)

[4] Shirataki Research Group. 1963. Study of the Shirataki site. (J)

[5] Goto T, Tomikawa T. 1983. Obihirokuko-minami A site. Tokachi Shicho. (J)

[6] Yoshizaki M. 1974. Shukubai-sankakuyama. Chitose city Board of Education. (J)

[7] Miya H, editor. 1985. Hirosato 8 site (II). Kitami city Board of Education. (J)

[8] Yamahara T, editor. 1992. Kyoei 3 site. In Kamishimizu 2, Kyoei 3, Higashi matsuzawa 2, and Komyo 1 site. Hokkaido Archaeological Research Center. (J)

[9] Sato N, Kitazawa M, editors. 1985. Obihiro-Akatsuki site. Obihiro city Board of Education. (J)

[10] Sato N, Kitazawa M, editors. 1986. Obihiro-Akatsuki site 2. Obihiro city Board of Education. (J)

[11] Sato N, Kitazawa M, editors. 1987. Obihiro-Kamiitaira site 2. Obihiro city Board of Education. (J)

[12] Sato N, Kitazawa M, editors. 1986. ObihiroKuko-minami B site. Obihiro city Board of Education. (J)

[13] Kitazawa M, Yamahara T, editors. 1995. Obihiro Minamimachi site. Obihiro city Board of Education. (J)

[14] Tamura T, editor. 1994. Excavation in the Marukoyama site. Obihiro city Board of Education. (J)

[15] Oshima Y, editor. 1997. Osatsu 16 site(2). Hokkaido Association for Cultural Properties. (J)

[16] Terasaki Y. 1990. Kamioka 2 site. Imakane city Board of Education. (J)

[17] Naganuma T, editor. 1985. Pirika 1 site. Hokkaido Archaeological Research Center. (J)

[18] Naganuma T, editor. 1988. Isikawa 1 site. Hokkaido Archaeological Research Center. (J)

[19] Onuma T, Chiba E, Endo K, Tachikawa T, Kumaya H, Hanaoka M. 1988. Shinmichi 4 site. Hokkaido Archaeological Research Center. (J)

[20] Tsuji H, editor. 1985. Oribe 16 site in Oribe site group. Kamishihoro-choBoard of Education. (J)

[21] Naganuma T, Koshida M, Sato T, editors. 1999. Nitto site. Hokkaido Archaeological Research Center. (J)

[22] Fukui J, Koshida K, editors. 1999. Kashiwadai 1 site. Hokkaido Archaeological Research Center. (J)

[23] Sagawa S, Nakata Y, Kageura O, Hanaoka M, editors. 2000. Miyako site. Hokkaido Archaeological Research Center. (J)

[24] Kitazawa M, Yamahara T, Kondo Y, Warashina T, editors. 1998. Obihiro-Kawanishi C site. Obihiro city Board of Eduation. (J)

[25] Kitazawa M, Sasajima K, Warashina T, editors. 2000. Obihiro-Kawanishi C site 2. Obihiro city Board of Eduation. (J)

[26]Yamahara T. 1999. Obihiro-Ochiai site 2. Obihiro city Board of Eduation.(J)

[27]Kitahara M. 2001. Obihiro-Beppu 1 site. Obihiro city Board of Eduation. (J)

[28] Taniguchi Y, editor. 1999. Archaeological research at the Odai Yamamoto I site. Odai Yamamoto I site Excavation team. $(\mathrm{J} / \mathrm{E})$.

[29] Takahashi Y, Kikuchi K, editors. 1999. Tougeyamabokujyo 1 site, A area. Iwate Archaeological Research Center. (J)

[30] Kikuchi K, Hashiba N, Takahashi Y, editors. 1996. Kashiyamatate-ato Archaeological Research Reports. Iwate Prefectural Archaeological Research Center. (J)

[31] Murakami T, editor. 1999. Mimitori 1 site, B area. Iwate Prefectural Archaeological Research Center. (J)

[32] Assosiation for Field Archaeologist Network. 1996. Archaeology and Numerical Dates. (Abstracts and Data) 40th Meeting at Takatsuki, $17 \& 18$. August 1996. (J)

[33] Japan Association for Quaternary Research. 2000. 14C ages of the Japanese Prehistory.

[34] Kondo N, Kobayashi H, editors. 1992. Simomouchi site. Nagano Prefectural Center for Archaeological Research . (J)

[35] Suto T. editor. 1999. Happusan site group. Saku city Board of Education.(J)

[36] Tani K. editor. 2001. Kosakayama site. Nagano Prefectural Archaeological Research Center. (J)

[37] Tsuchiya S, Tani K, editors. 2000. Hinatabayashi B, Hinatabayashi A, Nanatsuguri and Ohira B site. Nagano prefectural Archaeological Research Center. (J)

[38] Tani, k. (ed.) 2000 Uranoyama, Higashiura, Okuominami and Uenohara site. Nagano Prefectural Archaeological Research Center. (J)

[39] Tsuchiya S, Otake N, Tani K, Nakajima E, Totani Y, editors. 2000. Kannoki and Nishioka A site. Nagano Prefectural Archaeological Research Center. (J)

[40] Tsutiya S, Nakajima E, editors. 2000. Seiko Sansou A, Seiko Ssansou B, Nishioka A, Kannoki, Uenohara, Okubo-minami, Higashiura, Uranoyama, Harinoki, Odaira B, Hinatabayasi A, Hinatabayasi B, Nanatsuguri and Fukoda site. Nagano Prectural Archaeological Research Center. (J)

[41] Muraishi M, editor. 2000. Yokohari-maekubo, Yoneyama and Yokohari-nakayama site. Yamanashi prefectural archaeological research center. $(\mathrm{J})$ 
[42] Hosono T. 1999. Excavations at Kogure-Higashi-Arayama site. 11th Meeting for Palaeolithic Cultures Resarch in Nagano Prefecture. (Abstracts)(J)

[43] Nakatsu Y, Kobiki H. 1992. Tanashi Minami-cho site. Excavation committee for sites on Tokyo public school ground. (J)

[44] Oda S. 1980. Nishinodai Loc. B. Tokyo Metoropolitan Board of Education. (J)

[45] Suzuki Site Publication Committee. 1978. Suzuki site I. Suzuki Site Publication Committee. (J/E)

[46] Excavation group for Tokyo Astronomical Observatory site. 1983. TokyoÅ@Astronomical Observatory site. Excavation group for Tokyo Astronomical Observatory site. (J)

[47] Sakairi T, Ito F, Orikasa A. 1977. Takaidohigashi-chushajo-nishi site. Tokyo: Takaido Higashi Chushajo Nishi Site Excavation Project. (J)

[48] Itano S, editor. 1999. Hikageyama site. Site research association of Nishi-Kokubunji area. (J)

[49] Kurihara N, editor. 1998. Carbonized wood embedded in the loam layer from the site group among Yoda by-path project. KANAGAWA Archaeology Foundation. (J)

[50] Tsuji S. 2000. From radiocarbon dates to calender years: for the estabilishment of chronologies in 21 st century. In $A$ chronicle of archaeology 2000. Kawai, N. (ed.) Asahi Shinbun.

[51] Ichikawa M, Suzuki J, Yoshida M, editors. 1998. Kitahara (No. 10, 11 North) site. in The Miyagase site group. KANAGAWA Archaeology Foundation. (J)

[52] Suzuki J, Ichikawa M, Sanpei Y, editors. 1997. Nakappara and Ueppara site. in The Miyagase site group. KANAGAWA Archaeology Foundation. (J)

[53] Ikeda O, Sunada Y, editors. 2000. Heiwazaka site. KANAGAWA Archaeology Foundation. (J)

[54] Mine O, Hatanaka T, Izeki F, editors. 1999. Fukudaheininoku site. KANAGAWA archaeology Foundation. (J)

[55] Suzuki T, Ito T, Maejima H, editors. 1999. Hatunegahara site. Mishima city board of education. (J)

[56] Togashi T, Watase O, Sato K, Kasai M, Morinaga H, Yamashita H, editors. 1998. Takamigaoka (III, IV) site. Shizuoka Prefectural Archaeological Research Center. (J)

[57] Sasahara Y. 1999. Nishibora site, B area. Numazu city Board of Education. (J)

[58] Kawamichi H, Araki N, editors. 1998. Chaen site. Kishiku town Boardof Education. (J)

[59] Murasaki T, editor. 1998. Mimikiri site. Kumamoto Board of Education. (J)

[60] Ikeda T, editor. 1999. Ishinomoto site group (II). Kumamoto Board of Education. (J)

[61] Association for Field Archaeologist Network. 1987. Issues of Tephra and Archeology. (J)

[62] Dogome H. 1998. Upper Paleolithic Culture in Tanegashima Island. Annual Meeting of the Japanese Archaeological Association held in Okinawa, 1998. (Abstract) (J)

[63] Dogome H, editor. 2000 . Yokomine C site. Minamitane town Board of education.(J)

[64] Dogome H. 1998. Upper Paleolithic Culture in Tanegashima Island. Annual Meeting of the Japanese Archaeological Association held in Okinawa, 1998.(Abstract) (J)

[65] Sato H. 1999. The transition from Middle to Late Paleolithic in southwestern Japan. in From Souzudai to Kamitakamori: World Views on the Early and Middle Palaeolithic in Japan. :73-78, Tohoku Fukushi University:Sendai.(J)

[66] Nagano T. 2000. Chyochi site. Kiiri-cho Board of Education. (J) 


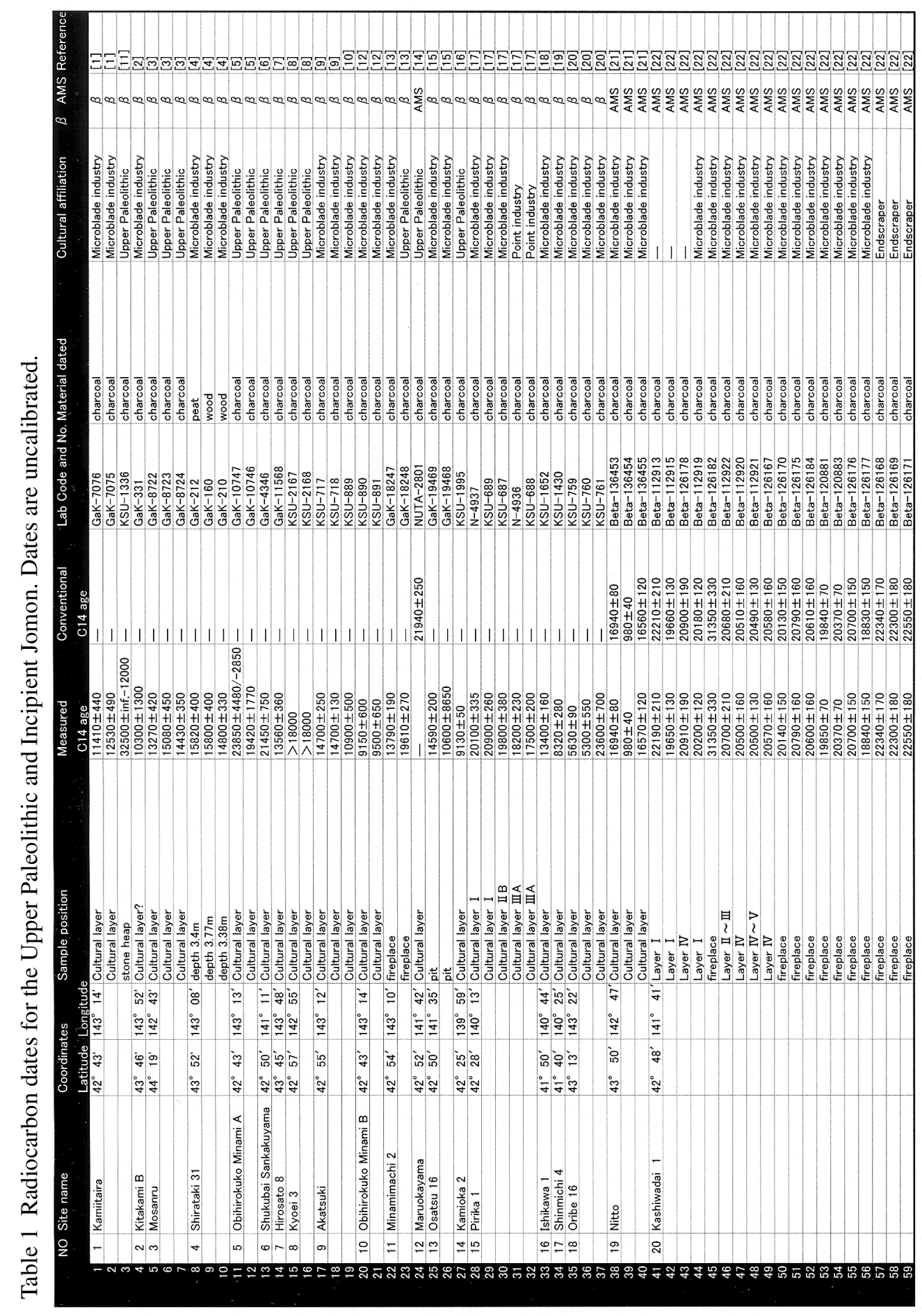




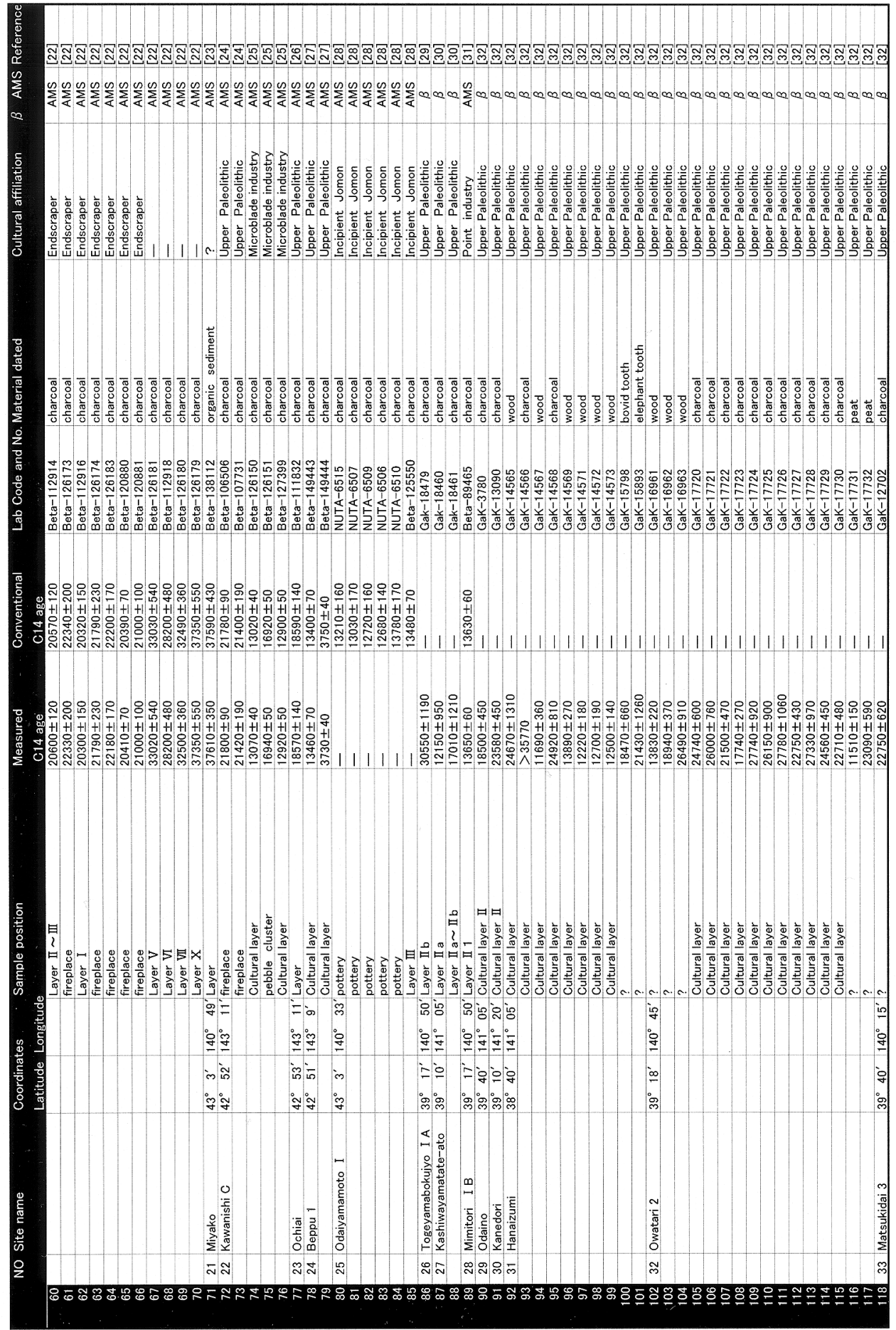




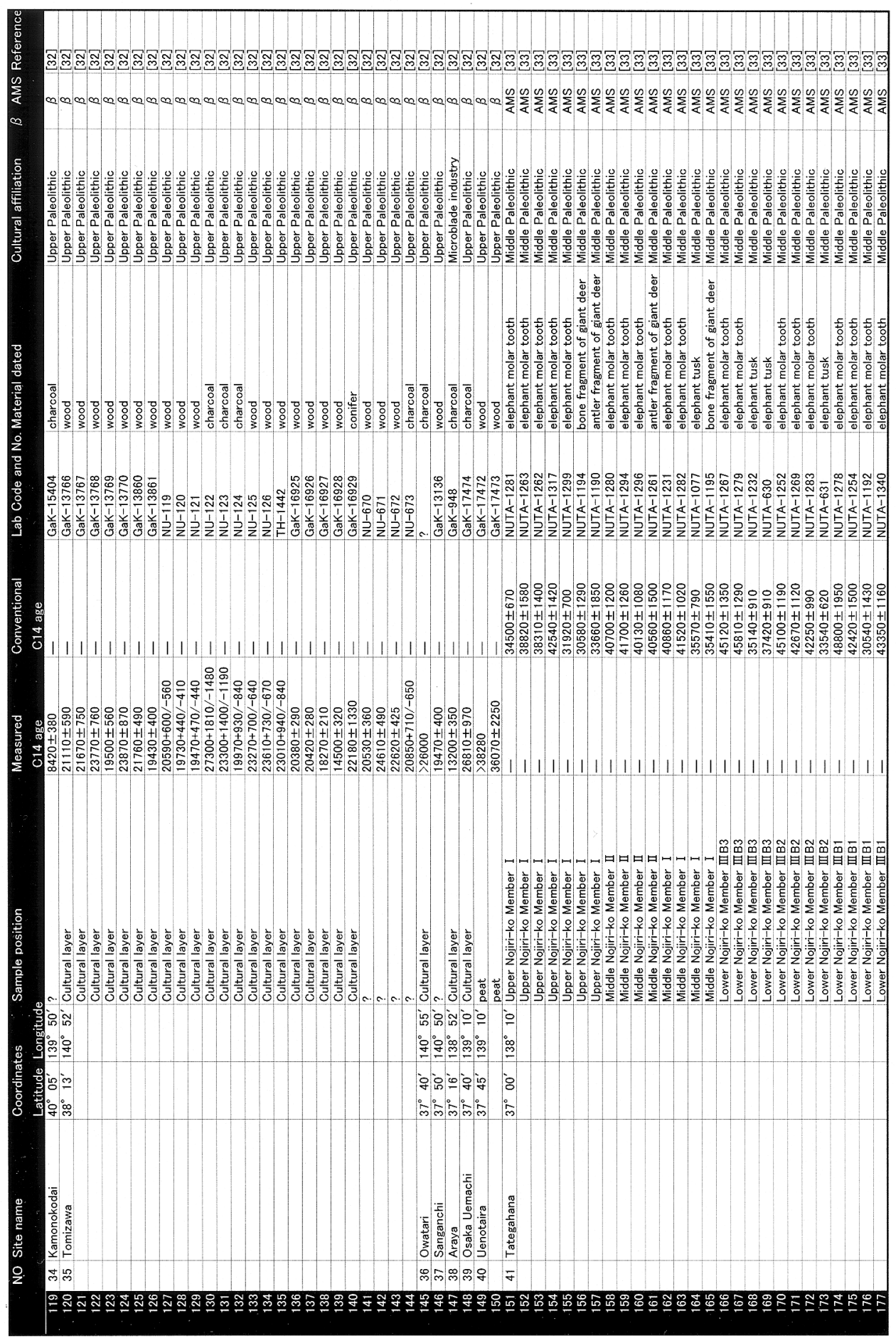




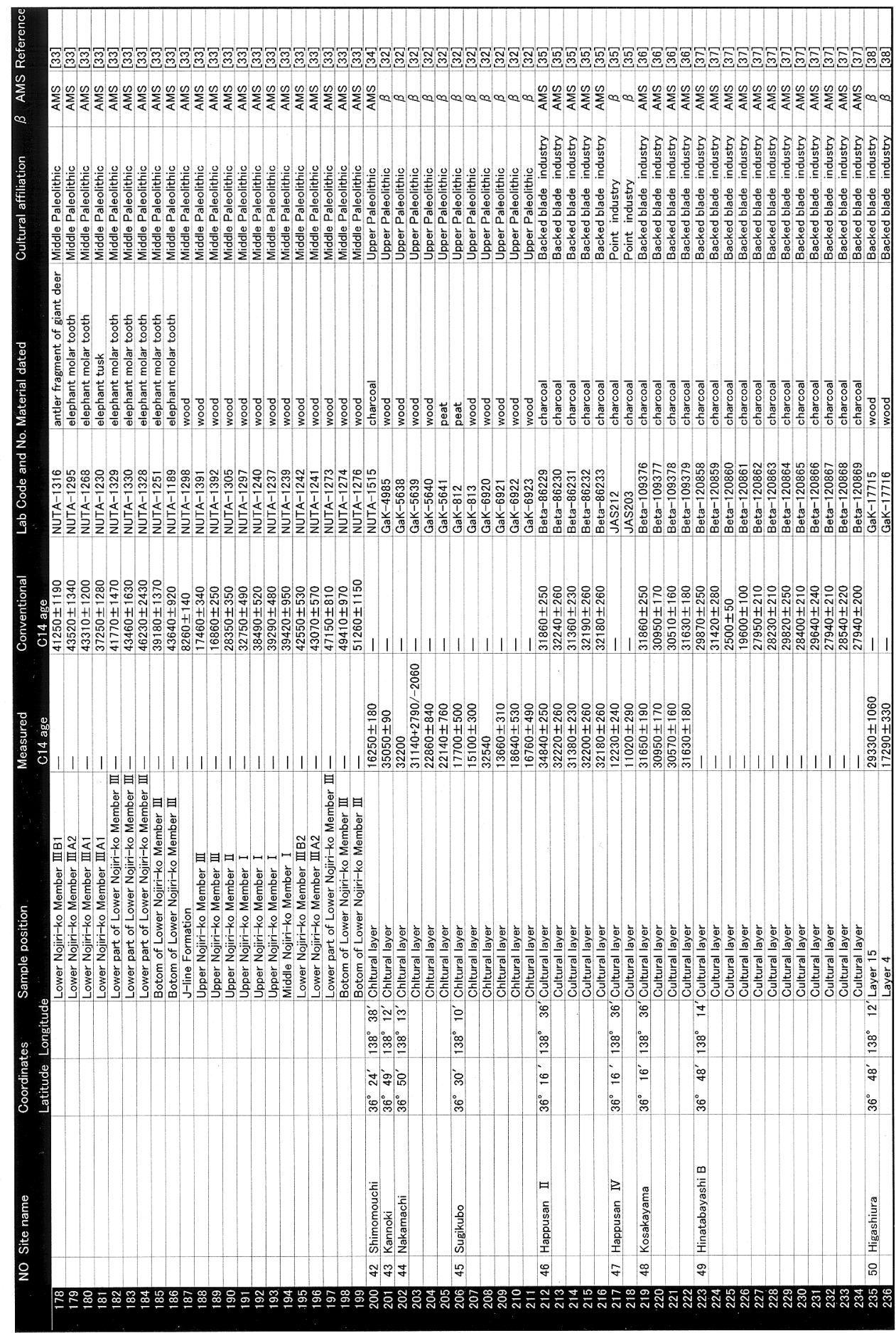




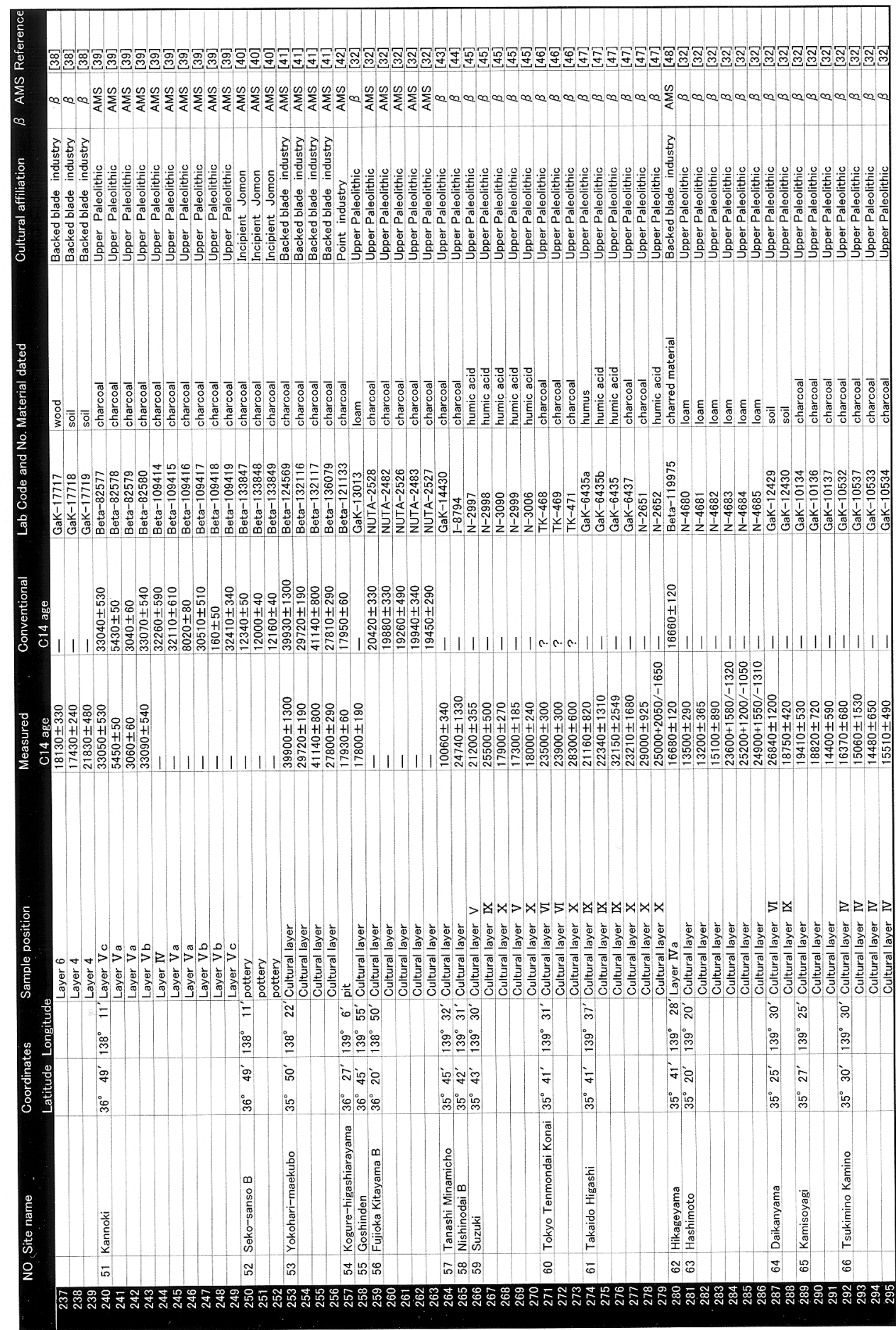




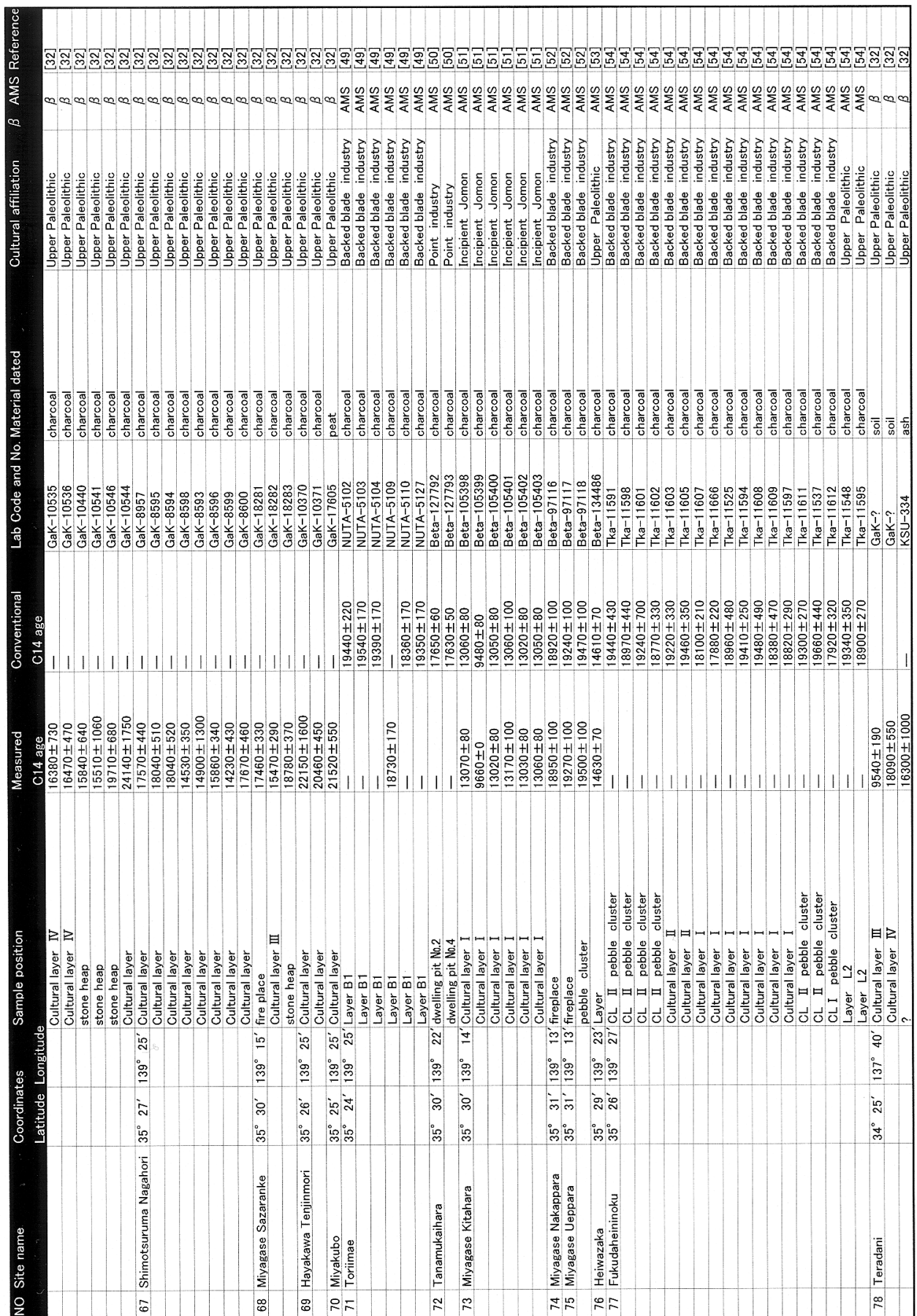

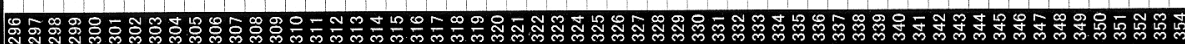




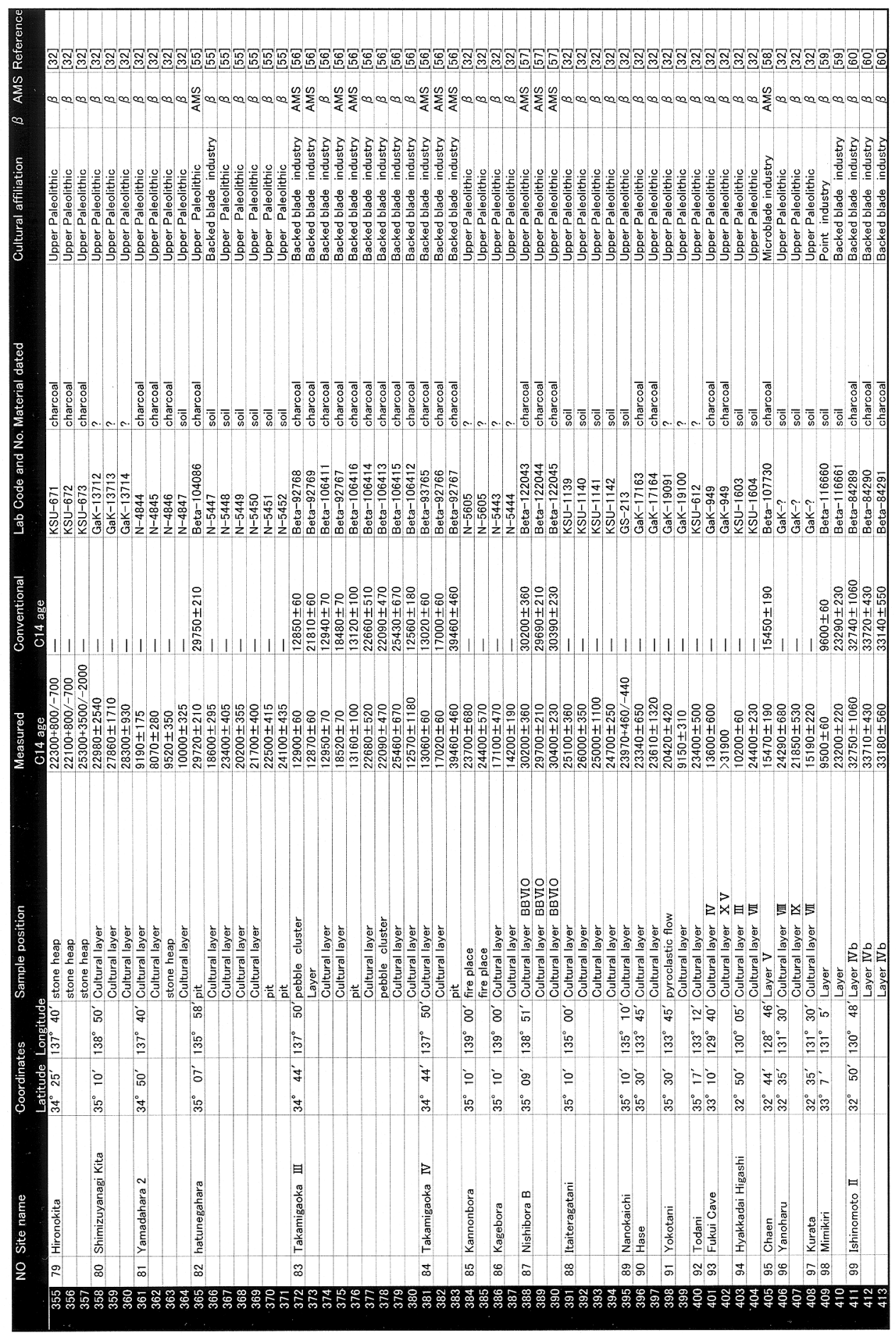




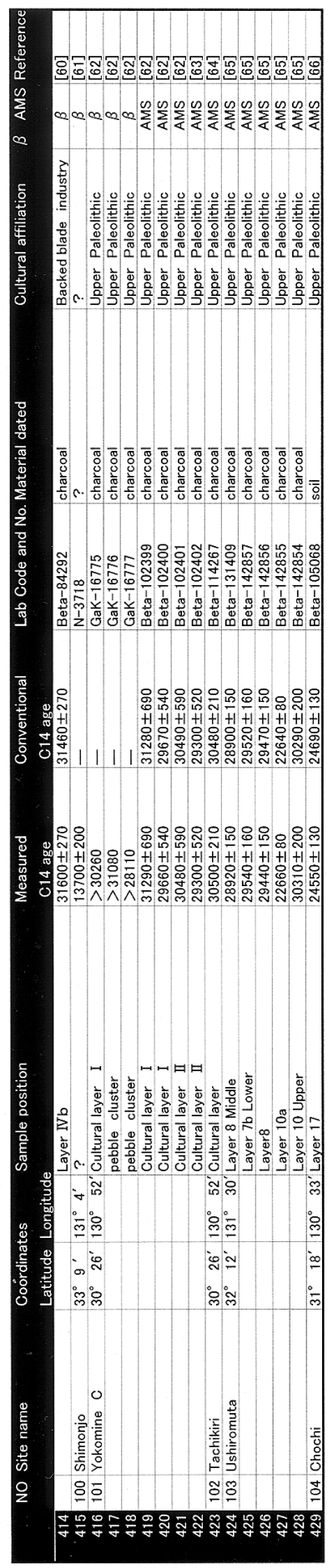

